\title{
Introduction to the Theory of Economic Dysfunction
}

\section{Sergey Nikolaevich Silvestrov}

Financial University under the Government of the Russian Federation, 125993, Russia, Moscow, Leningradsky Prospect, 49

\section{Alexey Grigorievich Zeldner}

Institute of Economics of RAS, 117218, Russia, Moscow, Nakhimovsky Prospect, 32

\section{Vladimir Sergeevich Osipov}

\section{Doi:10.5901/mjss.2015.v6n3p394}

Institute of Economics of RAS, 117218, Russia, Moscow, Nakhimovsky Prospect, 32

Plekhanov Russian University of Economics, 117997, Russia, Moscow, Streamyanny Pereulok, 36

\section{Abstract}

The methodological article considers the theoretical and practical aspects of the formation of economic dysfunction in the process of economy's reforming. This article attempts to classify the factors of dysfunctions in detail of basic directions to overcome dysfunctions in economic development. Theory of economic dysfunction is based on the achievements of sociology, biology, physics, chemistry, and is being the result of interdisciplinary research. Consideration of economic dysfunction allows to elaborate the concept of economic development policies and strategies in certain areas of the national economy.

Keywords: economic dysfunction, economic development, institution, public-private partnership

\section{Introduction}

Sustainable functioning of any system requires clear interconnection and interdependence of all its elements, aimed to achieve the set goals, whether in economics, biology or other fields. However the notion "system" itself should not be reduced only to its structural elements. It is also a set of relations between these units, which seems fundamental in assessing the system functioning, especially in the long turn. The economic system is an open dynamic system; it implies the existence of institutes and mechanisms which constantly maintain its stability [Silvestrov, 2007]. Aspiration to maintain a sustainable equilibrium state is a characteristic and a common feature organically inherent in all systems, including economic ones.

The concept of "social institute dysfunction" was introduced by H. Spencer (Herbert Spencer (1820-1903) English sociologist and philosopher. (Sociology as a subject of study. SPb. 1836. Fundamental Basics. SPb. 1897. and ect.)) to sociology as a science of society evolution laws. He considered this concept to reflect a condition when an appropriate institute brings harm instead of benefit to the society. According to $\mathrm{H}$. Spencer dysfunctions occur when there is a redistribution of functions between the newly created and already functioning institutes, under any attempt of an institute to monopolize functions, when some institutes do not comply with social need. Social institution activity is considered functional if it contributes to the stability maintenance and social integration. It can be considered as dysfunctional, if it aims at destruction rather that preservation. Increase of dysfunctions in social institutes activities leads to social disorganization of the society [Zeldner, 2013].

R.King Merton the Nobel Prize in Economics winner was also a follower of biological approach to social life. "In any given case the behavior of an object can have both functional and dysfunctional consequences, leading to a difficult and important issue of criteria development for assessing the clear equilibrium of a complex of consequences. "Functions are observed consequences that facilitate the adaptation of a system; and dysfunction reduce the system adaptation or adjustment" [Merton, 1949]. In fact, the system adaptation to external influences reduces.

\section{Methodology}

The system becomes imbalanced when it deviates temporarily, as a result of random fluctuations, from the norms of its own norms, its own equilibrium in a broad sense. If natural disasters can be estimated as random phenomena affecting 
all the global systems, the normal functioning of an economic system is seriously influenced by a set of factors, including subjective ones. Consequences arising from subjective intervention in economic processes, depending on the level of expertise of the subjects making crucial decisions without consulting the wider scientific community and the civil society institutions, lead to the accumulation of destructive trends in socio-economic development - economic dysfunctions. The system disturbance proceeds gradually due to actions of divergent interests, which eventually leads to its misalignment. System loses control and under the Ashby law "uncontrolled parts of any system fall off from it". This is a consequence of differentiated approach to the ways of ultimate goal achievement. By focusing on one object the other one disappears out of sight. If it is a high level of decision-making, there appears a system failure, abnormal functioning, structure distortion destruction leading to the system misalignment or, in biological terms, to its dysfunction.

It should be said that application of biological terms in social processes can be explained by the fact that in the late XIX - early XX century a new trend emerged and actively functioned in sociology - "social Darwinism". Adepts of this trend explained all social processes on the basis of biological nature of man. In fact, all the laws of human society development were reduced to the laws of biological evolution. In his organic theory of society H. Spencer compared society to a biological organism and stemming from this he believed that social life tends to equilibrium and harmony of class interests which sparked criticism of active Marxist disciples. As the founder of the organic school in sociology $\mathrm{H}$. Spencer interpreted the society class structure and the emergence of various institutions within it through analogy with living organisms, which are characterized by functions division among organs. However, he considered that the basic law of social development is the law of survival of the fittest societies [Merton, 1949].

Famous Le Châtelier principle, saying that a system undergoing external influences tends to return to its original state, helps to understand the impact of dysfunction on the system as an obstacle to the restoration of the system's initial state. From the evolutionary standpoint dysfunction prevents the economic system reform, as the system ability to recover is blocked [Hillman, 2003].

System misbalance means the appearance of activity results opposite to its intended functional purpose. In his book "Social Theory and Social Structure" (1957) R. Merton outlined three types of possible consequences of the system state under functional prerequisites violation: favorable, neutral and unfavorable, i.e. dysfunctional. According to R. Merton, the study of each factor affecting differently on the system needs to establish a "net balance of functional consequences," taking into account not only the favorable and neutral, but also the unfavorable outcomes.

It should be noted that modern foreign economists and sociologists seldom use biological terminology. The phrase "dysfunctional institutes" in relation to economics was used by Joseph Stiglitz, but only in the name of sub-section. In his lecture on the Nobel Prize in Economics receipt, considering the relationship of the state, the market and the "nonmarket" institutes, Joseph Stiglitz emphasized that, when theoretical understanding of the markets with imperfect information ineffectiveness increased, there have been several arguments against government intervention in the market [Stiglitz, 2002]. However, the analysis showed that the incentives and constraints related to the state operation are different from those operating in the private sector. Therefore, even when the state confronts the same information constraints as the private sector, welfare can be increased. Based on the conducted analysis the conclusion of the speech was that market mechanism may be proved effective only under very certain circumstances. Therefore, it is possible to avoid dysfunctions in the sustainable economic system development through combination of state, market and non-market institutions [Porter and Kramer, 2006; Sachs, 2011; Mulgan, 2008; Barber, 2008]. Hence the so-called market failures and failures of the state are reduced to the issue of combining the existing basic conditions for economic system suitability maintenance.

Among modern Russian economists biological terminology in social processes is limitedly used [Bulyga, 2014; Vorozheykina, 2014]. Dysfunction in the form of reducing economic development rates and living standards happens due to errors in reforms, shock privatization and price liberalization, failures in structural changes of the economy, underestimation of scientific and technical progress and etc.

In general, it should be emphasized that the basis of all dysfunctions are the mistakes made in the choice of development model, in the current system of governance and its impact on the managed object [Krisnawati et al., 2014; Bulyga, 2014; Osipov, 2013], in insufficient professional skills of social and economic processes governance. Given that Russia has not yet chosen the development model, economic dysfunction may increase constantly.

Any dynamic economic system along with the positive results achievement includes inevitable negative costs [Olson, 2000; North et al, 2009.]. At different stages of system operation it is noted as a rejection of various social norms, imperfection of institutes, corruption growth and etc. 


\section{Results}

We must distinguish corruption and state capture, differences between which are essential depending on economic dysfunction [Bhalla, 2001; Winston, 2006; Rice and Cooper, 2010]. Corruption is more likely the result of economic dysfunction. For example, if an official believes that the fulfillment of a public service costs more than the government plans to spend on its execution, there appears a wish to reward oneself for work. A false illusion of justice arises. From the common sense view point it is perfectly understandable that the government contracts conclusion for large sums of money causes a feeling of injustice, as the state official believes that business receives a contract "from the hands of an official", which means that the official should be remunerated. From the legal point of view it is corruption, but from the psychological point of view it is justice. This dilemma displays that the system of contract distribution includes economic dysfunction which generates unfavorable market-distorting consequences. Researchers N. Parison and N. Manning draw a line between the terms "state capture" and "administrative corruption". By the "state capture" they mean the actions of individuals, groups or companies both in the public and private sector aimed at influencing the formation of laws and regulations, decrees and other public policy for their own benefit. It is the result of illegal transfer of private benefits to public officials or the benefits concentration in the hands of the latter. By "administrative corruption" they mean the intentional introduction of distortion in the established order of existing laws, rules and regulations implementation, in order to provide benefits for the state or non-state actors after illegal transfer or diversion of private funds to public officials [Manning and Parison, 2003].

These deviations can be both a consequence of "trial and error development scheme", of so-called growth pains and of mistakes made by top-managers. Managerial errors in strategic development lead to social needs dissatisfaction, and as a consequence, to increase of social problems. If constructive solution is delayed the social role of the market begins to change in the society. There appears a market of paid services in all spheres, official corruption, shadow economy, lobby of abridged decisions and laws, abuse of monopoly power. Such transformation of the market social role and its impact on social development and consciousness is called dysfunctional market. Within these markets pure redistribution of wealth is performed, or certain benefits creation occurs with extremely high social and economic costs, which leads to economic stagnation rather than development. However the existence of dysfunctional markets has one positive side - they contribute to social stability, as each of these markets is based on a certain social consensus (social contract) between influential social groups. They reduce social discontent and create niches for certain social groups.

It should be noted that this "positive side" turns into control system and consolidation of oligarchy and bureaucracy. In the course of this change competitive conditions decline and, as a consequence, living standards decreases, all ethical norms are violated, development of small and medium-sized business and establishment of civil society institutes is inhibited. Quoting R. Merton "tensions accumulated in the social structure as a result of dysfunction ... will eventually lead to the institutional collapse and profound social changes" [Merton, 1949].

From the evolutionary theory standpoint dysfunctional tendencies are a characteristic of the development process. It is important to minimize the time period between dysfunction detection and solution of the misbalance in the system. Reduction of the dysfunction effects lies in timely analysis of economic system causal mismatch.

These deviations can be as a consequence of errors "development scheme trial and error", the so-called agerelated errors growth and mistakes made by managers of the upper level.

\section{Discussions}

Global economic dysfunctions may be generally classified into the following main blocks:

4.1. Underestimation of the role of the state as an institute that defines the global strategy and tactics for the reformed economy. During the transition from command economy to market relations everything that was associated with the Marxist concept of economic theory was rejected. However, the policy cannot be primer to economics. Given the spontaneity of the market economy "invisible hand", state political decisions and laws are necessary to manage it. This means that in the transition the state role increases and transforms into creation of institutional environment or institutional framework. It is important that with weak civil society institutions political leadership of the state would unite well prepared people in terms of moral and professionalism. It is good, when this political set is in the hands of sensible people. If not, then the "economy" change in isolation from all other social spheres, from the society culture leads only to complete disorganization and chaos, thereby undermining the fundamentals of the "economic" life itself. It is the background for all the long-term economic dysfunctions.

It should be recalled that the decline of Russian economy as a result of shock therapy was so deep that the main macroeconomic indicators have not yet reached the level of 1990s when the 2008 crisis happened. The majority of 
industries faced production simplification and suppression of high added value industries. Then the crisis followed, with the lag in innovation, refocusing on raw-material model of development and a constant declaration of the need to achieve the developed countries' horizon in terms of living standards.

Unfortunately, Russia failed to avoid serious social and economic consequences in the process of market relations formation, which are beginning to affect more and more the country development pace. However, with perseverance worthy of another application, the dogmas of market fundamentalism and the Washington Consensus are being imposed in Russia, despite their well visible consequences In his book "Freefall: Free Markets and the Sinking of the Global Economy" Stiglitz wrote: "We have created a society where materialism suppresses moral principles, where economic growth is not environmentally and socially sustainable, where we do not act as a community united by common goals, because of animal individualism and market fundamentalism that undermine any sense of solidarity, lead to rampant exploitation of vulnerable people and increase of social division" [Stiglitz, 2002].

The market role in the country development, the "invisible hand" of which was so hoped for by the Russian reformers, is strongly differentiated depending on the socio-economic level of the country. This leads to differentiation in approaches to defining the role of market and state. It should be also considered that the market applies modern financial institutions and corporate law. But according to Jeffrey Sachs it does not allow the modern system of market relations to provide "three main objectives - efficiency, equity and sustainability. Market system should be supplemented by public institutes, able to solve these problems. These institutions provide public goods (such as infrastructure), support scientific research and regulate the market. They provide fundamental justice of income distribution, and provide long-term assistance to enable the poor to escape poverty. They also contribute to the conservation of non-renewable resources for future generations" [Sachs, 2011]. Therein lays the solution to the problem of economic dysfunction - failures of the state.

4.2. Serious omission of Russian reformers was the underestimation of society interests and weak attempts to create civil society institutes. The account of the interests of society, not just the state, was considered by F.A. von Hayek. He noticed "... The conception of a constitution thus became closely connected with the conception of representative government, in which the powers of the representative body were strictly circumscribed by the document that conferred upon it particular powers. The formula that all power derives from the people referred not so much to the recurrent election of representatives as to the fact that the people, organized as a constitution-making body, had the exclusive right to determine the powers of the representative legislature" [Hayek, 1978].

One representative body sets "the rules of the game", the other produces hierarchy of priorities and social policies. The main thing is that the executive authority shall behave solely as a non-profit organization whose mission is to implement public interests. In this sense, government agencies are subject of the market. With regard to establishment of "the rules of the game", it is the domain of the legislative power, which cannot be subject of the market.

It should be agreed upon that the legislative power establishing the rules of the game, cannot act as a subject of market relations. But the fact that the executive power should be presented exclusively as a certain non-profit organization is problematic. Firstly, the subjects of the Russian Federation are obliged to participate commercial activities under crisis in order to support infrastructure through development of various forms of public-private partnership. Secondly, the municipal government with power, but without the necessary budgetary support, have to actively apply their potential by developing partnerships with small and medium-sized businesses, therefore maintaining social stability.

Separation of authorities' powers is a sign of a civilized state, where law has immutable priority, control over state activities is carried out by various civil society institutes. With this approach, the executive power acts as an equal to business subject of market relations. Lack of tangible civil society institutes, clear strategy and tactics of the transition from a command model to a mixed economy has led to a dramatic expansion of state economic dysfunctions.

Large business managed to impose its own rules and institutes on legislation and executive power, which are primarily focusing on the interests of large capital. At the same time not all the opportunities of rational correlation of state and market components were considered based on a mixed economy and development of public-private partnership.

Chinese experience of economic system transformation showed as gradual economic reform has created the basis for the formation of mixed economy with a Chinese character. In the process of reforms China managed to implement what is only constantly talked about in Russia - the economy restructuring by focusing on industrial policy. Combining high level of development of light industry, food industry and other non-extractive industries China managed to maintain positive GDP growth even during the systemic crisis (2008-2009).

The UN report "World economic and social review. Retooling Global Development" emphasizes that "... the market without a strong state leads to the replacement of irresponsible state power by unregulated private enrichment, leading to economic and social decline" [World Economic Outlook Supporting Studies IMF, 2000].

4.3. Economic dysfunctions in Russia were laid in parallel with the reforms during the transition from planned to market system. Weak understanding of the market relations nature by the majority of the population allowed to 
manipulate their consciousness, to impose the idea of market system, which would automatically provide social and economic sustainability. As the subsequent experience of the Russian economy showed, the spontaneous transition to the market was primarily intended solely for diminishing the planned state system, and no goals of economy restructuring and modernization, aimed at improving the quality of life were set.

Rapid redistribution of large property, allegedly an important obstacle to the planned economy restoration, allowed to concentrate substantial money assets in the hands of people close to the high-ups, but political risks in the period were rather enough and no one wanted to lose the assets. The property resale began, together with export of capital and finding ways of its rapid turnover, and this is by no means modernization, construction of new plants, but rather import, trade, catering.

Such reform was accompanied by the emergence of speculative financial sector, preferring quick cash flow and their minor use for investments in the real sector. This applied both to private capital and partially redundant public funds stocked in bonds, loans, etc. Focusing on quick profits with the absence of social brakes and appropriate level of culture stimulates capital outflow from the production sector into various financial speculative instruments. As a result, absence of long-term economic policy approach is becoming normal. Spontaneous economic reform without a clear development strategy could not but provide long-term economic disruption and destabilization of the Russian economy.

4.4. A serious strategic failure with far-reaching dysfunctional consequences for Russia has become the loss of rate and quality of scientific and technical progress, cuts of funding and amount of researchers, transition to purchasing foreign technology and end-stage products. In a stable market economy operating with the development of scientific and technological progress the role and significance of the main production factors is changing. And unlike Russia the contribution of developed countries to the progress of science, modernization of economy is constantly increasing. It roots prolonged dysfunctional social and economic trends in Russia for decades ahead.

The study of economic growth conditions and factors of for a significant period of time in developed market economies showed that traditional factors such as capital and labor, provided only $12 \%$ of economic growth in 19091949, according to R. Solow. The major part of growth was predominated by such a complex factor as technological progress. But technological progress requires significant investments, both private and public. Such factors of economic growth, as the impact of education and technological innovation, provide labor productivity growth. But it requires substantial incentives encouraging market entities to adopt new technologies. These incentives, according to neoinstitutsionalists, are coming to the forefront and encouraging productive activities. And that, ultimately, determines "the rules of the game" in society during institutions and mechanisms creation. Incentives from scientific and technological progress promotion in Russia under insufficient funding for innovation and absence of real competition work poorly. It is a consequence of the lack of managerial competence, willpower and national pride, which leads to long-term dysfunctional social and economic consequences.

Losing pace of technological development in the context of global coverage of innovation, technology and other goods world market by transnational corporations leads to the corresponding coordinated tactics of TNCs, allowing to place goods production and assembly plants in countries with lower costs and to sell with maximum efficiency. Cost minimization and profit maximization allows TNCs to allocate significant resources for the development of science, innovation and the latest technology, and to stay ahead of many developing countries (including Russia) in terms of scientific and technical achievements. So is the backlog in innovations laid with all the related consequences, assigning the role for Russia as a raw materials supplier for the developed countries with growing imports of products of mass consumption.

4.5. Among the dysfunctions, having prolonged impact on the economy, is also the lack of real competition in Russia in the process industries, mostly in the oil and gas industry and a number of other industries (an exception is the competition of large retail chains). Lack of competition is directly affecting the country innovative development, labor productivity and production costs. If during the reform a clear course was adopted to create conditions for development of a coherent chain (competition-innovations-modernization-productivity and labor costs) it would not be said that the Russian economy is stagnating and is actually on the verge of crisis in terms of the costs dynamics.

Rising costs with continuous increase of tariffs and prices of natural monopolies, aging assets and too slow modernization (including financial restrictions) could not but cause increased costs: the whole economic policy of 19911993 reformers led to this. We cannot agree with the fact that a constant source of imbalance remains the advancing growth of wages purchase power over labor productivity. Russian salaries and pensions can be mentioned in apologetic mood. Among the world developed countries without Russian natural resources, the country's population (not counting officials and managers of large companies) is in the end of the list in terms of income. 


\section{Conclusion}

Prominent German economist and statesman L. Erhard believed that "prosperity for all" and "prosperity through competition" are inextricably linked. One is the goal, the other - the path leading to it. Competitiveness of the economy provides a constantly flowing innovation and modernization process, ensuring labor productivity growth. Innovations are the central factor in labor productivity increase, without which competitive economy cannot exist. That's why the most important criterion of innovation efficiency is the extent to which innovation increases the competitiveness of industry or economy in general. Ensuring free competition is one of the most important tasks of the state based on free social order. It is no exaggeration to say that a law prohibiting cartels would have been the most necessary economic constitution. If the state loses in this area - it will soon be the end of social market economy. "The state should intervene in the market only to the required extent needed to maintain the competition mechanism operation or to control the markets where the conditions for free competition are not feasible ... if economic monopoly are formed, they should be abolished, and to do so they must be subject to state supervision"[Erhard, 1957].

Full-scale monopolization of the Russian economy and the lack of real competition leads to a constant price growth for products and services of natural monopolies and state corporations. Further on this flywheel spins the rising costs and, as a result, prices in the production of consumer goods, with the people being in the end of the chain facing inflation costs and increase of retail prices.

World's leading companies are forces to active modernization and innovation by competition for the consumer and, as a consequence, for profit. In Russia competition is substituted by monopoly collusion, tolerance of authorities and weak penalties. Consequently, it is the state, its ability to create a competitive climate, that is in charge of solving the issue of attracting private investment in innovation activities.

\section{References}

Silvestrov S.N. (2007). Economic Policy of Development and Indicative Planning. Society and Economy. \# 11-12. (119-137).

Krisnawati, A., Yudoko, G., Bangun, Y.R. (2014). Development path of corporate social responsibility theories // World Applied Sciences Journal, 30 (Innovation Challenges in Multidiciplinary Research \& Practice): 110-120. DOI: 10.5829/idosi.wasj.2014.30.icmrp.17

Bulyga R.P. (2014). Business Audit: The New Concept of the XXI Century. World Applied Sciences Journal 29 (5): 619-622. DOI: 10.5829/idosi.wasj.2014.29.05.13890

Porter M. and Kramer M. (2006). Strategy and Society: Creating and Sustaining Superior Performance. The Link Between Competitive Advantage and Corporate Social Responsibility. Harvard Business Review, December: 5. http://www.compromisoempresarial. com/wp-content/uploads/strategy-society.pdf

Zeldner A.G. (2013). Destructive Tendencies and Constructive Opportunities to overcome them in the Economic System of Russia. Moscow, Economika.

Sachs J. D. (2011). The Price of Civilization. New York: Random House.

Stiglitz J. (2002). Information and the Change in the Paradigm in Economics. American Economic Review, American Economic Association, vol. 92(3), pages 460-501, June.

Manning N, Parison N. (2003) International Public Administration Reform: Implication for the Russian Federation. World Bank.

Merton R.K. (1949). Social Theory and Social Structure. New York: Free Press.

Osipov V.S. (2013). The Wheel of Coompetition as a New Instrument of Strategic Management. World Applied Sciences Journal, 27 (8): 1083-1086. DOI: 10.5829/idosi.wasj.2013.27.08.13735

Olson M. (2000). Power and Prosperity. Outgrowing Communist and Capitalist Dictatorships. New York. Basic Books.

North D.C., Wallis J.J., Weingast B.R. (2009). Violence and Social Orders. A Conceptual Framework for Interpreting Recorded Human History. Cambridge University.

Bhalla A.S. (2001). Market or Government Failures. An Asian Perspective. Palgrave.

Winston C. (2006). Government Failure versus Market Failure. Microeconomic Policy Research and Government Performance. Brookings Institution Press.

Rice R.E., Cooper S.D. (2010). Organizations and Unusual Routines. A Systems Analysis of Dysfunctional Feedback Processes. Cambridge University Press.

Mulgan G. (2008). The Art of Public Strategy. Mobilizing power and knowledge for the common good. Oxford University Press.

Erhard L. (1957). Wohlstand für Alle. Econ Verlag, Düsseldorf.

Vorozheykina T.M. (2014). Actual tasks of food security. Economy and Entrepreneurship. \# 1-2. P. $46-48$.

Barber M. (2008). Instruction to deliver. Fighting to transform Britain's public services. Methuen.

Hillman A.L. (2003). Public finance and public policy. Responsibilities and limitations of government. Cambridge university press.

Hayek F.A. (1978). The Constitution of Liberty. The University of Chicago Press.

World Economic Outlook Supporting Studies IMF. 2000. https://www.imf.org/external/pubs/tt/weo/2000/01/pdf/chapter5.pdf 